\title{
What I Learnt About How I Learnt About Behavioral Economists
}

\author{
ZARA THOKOZANI KAMWENDO \\ ST. JOHN'S COLLEGE, DURHAM UNIVERSITY
}

\begin{abstract}
This paper is a discussion of the role of the experimental methods and the dissemination practices of behavioral economists in capturing public imagination. The paper is framed by auto biographical accounts of two episodes in my own exploration of behavioral economics as a topic of study: participating in a MOOC on the basics of behavioral economics and sharing my work in progress to a group of staff and students in Singapore. Drawing on Shapin and Shaffer's notion of "virtual witnesses" (Shapin and Shaffer 1985) I develop the argument that a consequence of the dissemination practices of the Heuristics and Biases Program is the creation of both "virtual subjects" and "virtual experimenters." I then give an account of Thaler's use of rationality and Kuhnian paradigm shifts as a rhetorical device to persuade mainstream economists and policy makers of the value of behavioral economics and to establish the narrative of behavioral economics as critics of neo-classical economics. I argue that the reflexive approach adds to accounts of the success of behavioral economics as a story of persuasive techniques of behavioral economists embedded in their practices of experimentation and dissemination.
\end{abstract}

\section{Keywords}

behavioral economics; heuristics and biases; dissemination; reflexivity; virtual subject

\section{Introduction}

Contemporary behavioral economics lives in a space where policy and popularization converge. Books that popularize the field and its psychological foundations abound. Thomas Gilovich's How We know What Isn't So: The Fallibility of Human Reason in Everyday Life was published in 1993 is one of the earliest examples (Gilovich 1993). Two decades later, the list of books written for a lay audience with the purpose of disseminating selected parts of behavioral economics and the psychology that the field is built on had grown exponentially (examples include Shiller 2000; Gladwell 2005; Ariely 2008; Brafman and Brafman 2008). The list now also includes books by two of the field's most central actors, Thinking, Fast and Slow (2011), by psychologist Daniel

ZZara Thokozani Kamwendo, Email: z.t.kamwendo@outlook.com

Copyright (C) 2020 (Zara Thokozani Kamwendo). Licensed under the Creative Commons Attribution Non-commercial No Derivatives (by-nc-nd). Available at estsjournal.org. 
Kahneman, ${ }^{2}$ and Misbehaving: The Making of Behavioral Economics (2015), by behavioral economist Richard Thaler.

Behavioral economics as a field has also steadily gained traction in the public policy arena, with countries like the UK, the US, and Singapore in the lead (Straßheim 2019; Kusch 2007). ${ }^{3}$ In 2010 the UK government under the leadership of Prime Minister David Cameron set up a self-contained policy unit: the Behavioral Insights Team to develop and implement policies with this conception of the irrational human in mind. ${ }^{4}$ The nickname the "Nudge Unit" for this policy department came from what is perhaps the most popular and influential book on the application of behavioral economics in public policy: Richard Thaler and Cass Sunstein's Nudge: Improving Decisions About Health, Wealth and Happiness (Thaler and Sunstein 2008). ${ }^{5}$

There are now a number of scholars who have provided accounts of the emergence and use of behavioral public policy in a variety of contexts (Oliver 2017; Straßheim and Beck 2019; Jones et. al. 2013; Barton, A and Grüne-Yanoff 2015) as well as intellectual histories of behavioral economics that examine the discipline's relationship with other approaches to economics and decision theory (Sent 2004; Pooley and Solovey, 2010; Heukelom 2014).

Some of these authors, like myself, remain skeptical of the project as a whole, questioning the underlying ethical and political norms of behavioral choice interventions (Jones et. al 2013; White 2017, 2019; Bovens 2009), and of behavioral public policy as an expression of neoliberalism (Whitehead et. al. 2018). Criticism has also been leveled at the efficacy of behavioral economics when applied to public policy (e.g. Goodwin 2012), including criticisms of its focus on individual behavior at the expense of broader cultural and institutional change (Straßheim 2020).

Much literature explains the appeal of behavioral policies in terms of the costeffectiveness of behavioral policies and their general alignment with liberal (and neo-liberal) norms. Graf (2019) has also recently offered a nuanced account of the rise of behavioral public policy as part of a general trend toward behavioral approaches to regulation that were attractive to policy makers "in an age of deregulation and marketization" (Graf 2019, 25).

'Thinking, Fast and Slow quickly became very popular when it was first published. It was selected by the New York Times Book Review as one of the best books of 2011, was a Globe and Mail Best Books of the Year 2011 title, one of The Economist's 2011 Books of the Year, one of The Wall Street Journal's Best Nonfiction Books of the Year 2011, and was the winner of the 2011 Los Angeles Times Book Prize for Current Interest.

${ }^{3}$ Incidentally, these are all countries that feature in this paper.

4 On May 1, 2013, it was announced that the Behavioural Insights Team would become a joint-venture company, owned in equal thirds by a private investor, the members of staff, and the government. The split took effect February 5, 2014.

${ }^{5}$ Thaler was awarded the Nobel Prize in Economic Sciences in 2017. The award was in large part motivated by the work he has done to show "how policies based on insights from behavioral economics can help people make better decisions" (Advanced information. NobelPrize.org. Nobel Media AB 2019). Accessed June 13, 2019. https: / / www.nobelprize.org/prizes/economic-sciences/2017/advanced-information/ 
I arrived at the history of behavioral economics as a topic from a place of skepticism and bemusement about what I perceived them to be claiming to do, namely, measuring human rationality. It provoked me that a group of psychologists and economists would claim the ability to define rationality, let alone to measure it, only to conclude that we, humans, are all irrational. How and why did behavioral economics come to my attention in the first place and how was I enrolled in behavioral economics so quickly? How can I explain the quick shift that I experienced from feeling bemused and perplexed about what behavioral economists say and do, to it all making perfect sense to me?

My aim in this paper is to contribute to accounts in the literature noted above by focusing on the reasons why behavioral economics has been so successful at capturing public imagination. I do this by asking what can be learnt about the experimentation and dissemination practices of behavioral economics by reflecting on my own engagement with the discipline.

I begin with a reflection on my participation in a Massive Open Online Course (MOOC) on the basics of behavioral economics to explain how I arrived at the questions that led to writing this paper. I then discuss how the form of the experiments that underpin Kahneman and Tversky's research program informed their methods of dissemination, framed by a reflection on the choices I made when sharing my work in progress to a group of staff and students in Singapore. Drawing on Shapin and Shaffer's notion of "virtual witnesses" (Shapin and Shaffer 1985), I develop the argument that a consequence of the dissemination practices of the Heuristics and Biases Program is the creation of both "virtual subjects" and "virtual experimenters."

Finally, I turn to discuss how behavioral economists' primary audience in the early days of the formation of their discipline--neo-classical economists-required them to hone their skills of persuasion, and how that process relates to the interplay between rationality and irrationality as expressed in their dissemination practices. I conclude with a discussion about what the autobiographical account and the emphasis on experimentation and dissemination bring to our understanding of the history of behavioral economics. I reflect on the parallels between the selfconstructed narratives of behavioral economists and my perception of my disciplinary legacy in the Edinburgh School of STS.

\section{Between Provocation and Admiration, I Found a Question}

One of my earliest encounters with behavioral economics came when I signed up for a massive open online course or "MOOC" called A Beginners Guide to Irrational Behavior run by behavioral economist Dan Ariely at Duke University. I suspected it would be a fun way to familiarize myself with the substantive content of behavioral economics. I also thought it might be beneficial to writing a sociology of the field, to experience for myself how the "science of irrationality" was taught to a lay audience.

Being a student of behavioral economics for a time was both entertaining and enlightening. The course was designed to be both engaging and funny. The field was presented as an enjoyable and mischievous series of explorations of less than rational human behavior. Those of us who participated and handed in our assignments on time were congratulated for 
having successfully followed through on this exploration of our irrational selves with a "Statement of Accomplishment." Since the 17" of May 2013, I have been the proud owner of the following certificate:

\section{THOKOZANI KAMWENDO}

\section{HAS SUCCESSFULLY COMPLETED AN ONLINE NON-CREDIT COURSE OFFERED BY DUKE} UNIVERSITY.

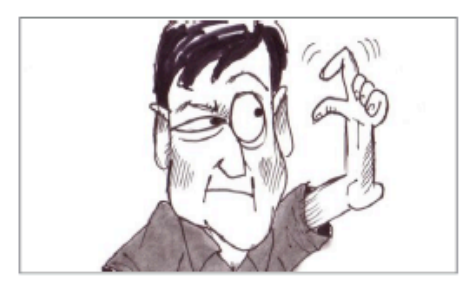

\section{A Beginner's Guide to Irrational} Behavior

Receiving this Statement of Accomplishment is an incredible achievement, and you should show it off to all your friends and hang it in your living room next to the display case of trophies that you must also own. The bar was high, and you leapt right over it. Way to gol

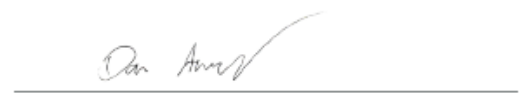

DAN ARIELY

PROFESSOR OF PSYCHOLOGY \& BEHAVIORAL

ECONOMICS

FUQUA SCHOOL OF BUSINESS

DUKE UNIVERSITY

DUKE UNIVERSTTY CANNOT GUARANTEE THE IDENTITY OF THE STUDENT TAKING THIS ONLUNE COURSE.

Figure 1: "A Beginner's guide to Irrational Behavior - Statement of accomplishment." Certificate of completed course issued by Coursera and Duke University.

I opted not to follow the instructions to hang this statement in my living room, but I did stick a copy of it on the wall next to my desk, partly because, like any good student, I was genuinely proud of myself for having completed the course and I wanted a reminder of how effective the course had been at keeping me engaged and getting me on board with the behavioral economics approach to human behavior.

The experience also highlighted how behavioral economists mobilize students' preexisting ideas and affects around the notion of rationality in the way they disseminate their knowledge. This was particularly the case in the use of irrationality as a provocation-the very provocation that alerted me to the field in the first place. In short, the course highlighted, for me, the power of invoking rationality as a tool for recruitment into the field and capturing public imagination.

What's more, within that mobilization of rationality was a kind of interplay between rationality and irrationality that allowed the irrevocably irrational "me" to be recruited on the assumption that I would wish to do better, act more rationally, and be more rational. The course 
throughout (exemplified in the title) oscillated between urging acceptance of irrationality as a general human condition and finding and applying tools for overcoming it.

In the time it took to complete the course it struck me that the mobilization of the rational/irrational relation was used to justify a certain kind of knowledge making and its broader dissemination. In effect, what was proffered is the idea that humans are intuitively irrational, which, ironically, is evidenced in our belief in our own rationality, therefore, it is imperative that we (and as many people as possible with us) learn about our own irrationality because it is the only road to rationality open to us.

Those of us who had successfully completed the course did indeed seem to emerge as a group of people who were perhaps the most rational possible precisely because we had shown both a willingness to accept our irrational nature and to explore the limited ways available to resist it.

I was a self-proclaimed disciple of the sociology of scientific knowledge, heavily influenced by the "Strong Programme" (Bloor, 1991) and its emphasis on relativism and the symmetry principle. Embarking on a socio-historical study of the making of behavioral economics, I felt a resistance to the decidedly asymmetrical approach to the study of social phenomena advocated by behavioral economists. Yet, I also felt the power of a pull toward wanting to learn more about rationality in general, and my own rational failings in particular. Why? The answer lies at least partly in the experimental practices of the Heuristics and Biases Program, which constitutes the psychological foundations of behavioral economics.

\section{The Linda Problem: Persuasive Powers of the Heuristics and Biases Program}

The Heuristics and Biases Program is the result of the collaboration between psychologists Daniel Kahneman (1934-) and Amos Tversky (1937-1996), which began in the early 1970's. Kahneman and Tversky were focused on showing evidence of descriptive deviations from normative decision rules. They worked from the premise that informal human reasoning is guided by deepseated intuitions that differ from the rules of formal logical and statistical inference. They hypothesized that these intuitions tended to overrule the laws of formal logical and statistical inference even when individuals are familiar with those formal rules.

The terms "heuristics" and "biases" roughly denote "cause" and "effect" in the Heuristics and Biases Program. Individual heuristics were what Kahneman and Tversky conceived as components of the human intuitive interpretative framework, and the various biases were the kinds of systematic deviations from the rules of normative decision making that they produced. One of the clearest and most succinct definitions of the core premise of the Heuristics and Biases Program can be found in Kahneman and Tversky's 1974 "Judgment Under Uncertainty: Heuristics and Biases:"

People rely on a limited number of heuristic principles which reduce the complex tasks of assessing probabilities and predicting values to simpler judgmental operations. In general, 
these heuristics are quite useful, but sometimes they lead to severe and systematic errors (Tversky and Kahneman 1974, 1124).

The Heuristics and Biases Program was built on a series of experiments with human subjects, many of which took the form of quiz-like questions of probability, choice preference, or logical puzzles designed to confirm this core premise. One of Kahneman and Tversky's most frequently cited experimental tests is a decision problem called the "Linda Problem." In experiments using the simplest version of the Linda problem, subjects are presented with the following scenario:

Linda is 31 years old, single, outspoken and very bright. She majored in philosophy. As a student, she was deeply concerned with issues of discrimination and social justice, and also participated in anti-nuclear demonstrations (Tversky and Kahneman 1983).

The task is to choose the most probable of the following two options:

Linda is a bank teller.

OR

Linda is a bank teller and is active in the feminist movement.

(Tversky and Kahneman 1983, 299)

Kahneman and Tversky used the results of the "Linda Problem" to provide evidence of their first and most extensively developed heuristic: the representativeness heuristic. ${ }^{6}$ "Representativeness" is the idea that the probability of an event depends on the degree to which it represents the major characteristics of the population or process to which it refers (Kahneman and Tversky 1972). The "Linda problem" was designed to test systematic violations of the conjunction rule of probability. ${ }^{7}$ The rule goes as follows. In formal probability theory, instances of $\mathrm{A}+\mathrm{B}$ can never be more probable than instances of (only) A or (only) B, because the probability of any combination of events cannot be higher than the probability of its constituent events. ${ }^{8}$

${ }^{6}$ Kahneman and Tversky performed experiments using a number of variations on the Linda problem. The extended version included 8 different options for subjects to choose from. The version presented here is the simple version with only two options. Both versions are discussed in Tversky, A. and D. Kahneman. 1983. “Extensional Versus Intuitive Reasoning: The Conjunction Fallacy in Probability Judgment." Psychological Review 90(4):293-315.

- In the original experimental testing of the conjunction fallacy the two scholars alternated between the Linda problem and a scenario based on a fictive male character called Bill. Bill has not gained even half the traction that Linda has, and the test most commonly referred to in discussions about violations of the conjunction fallacy is the Linda problem. This is most likely because Kahneman and Tversky performed the experiment of the Linda problem in two versions. One extended version tested with both the fictive characters Linda and Bill, and another, simple one, performed only with the Linda scenario.

s Kahneman and Tversky first conducted experiments to test violations of the conjunction rule in Jerusalem in 1974. They later dedicated an entire paper to the exploration of the violations of the conjunction rule. See 
Historian Floris Heukelom (2012), when discussing the appeal of the Heuristics and Biases Program to economists. posits that alongside their reinterpretation of the normative and the descriptive and their use of highly intuitive examples in the design of the questionnaire, the form of Kahneman and Tversky's questionnaire-style experiments also played a central role. Compared to laboratory experiments that Kahneman and Tversky had both used in their research before their collaboration, the hypothetical quiz style experimental procedure was costeffective and quick to carry out since, pens, a few sheets of paper, and a couple of research assistants would suffice to administer the questionnaire. He also argues that another important advantage of their experimental style was how mobile the experiments were in that they could be done anywhere, as opposed to more lab-based experiments that required particular experimental setups (Heukelom 2012).

I agree that the persuasive power of the Linda Problem lies not just in the contents but also in the form of the experiments. But what is most crucial is what the hypothetical questions style allowed Kahneman and Tversky to do in the process of disseminating their results. I was alerted to the power of Kahneman and Tversky's style of dissemination the first time I caught myself using it to explain the Heuristics and Biases Program to an audience. While putting together a talk for a Work in Progress seminar at Tembusu College, National University of Singapore, in 2015, it struck me that the clearest and most engaging way to explain my object of study (the Heuristics and Biases Program) would be to simply put the short question/description of one of their experiments on a slide, and ask the audience to choose an answer.

Because this was essentially the format of the original experiments, my public demonstration of the Linda problem was as good as indistinguishable from the original experiment as it had been reported to me. In telling the story of the experiment in this way I had in effect inadvertently enrolled my audiences as subjects of the experiment that I was telling them about.

My point here is that this was also Kahneman and Tversky's style of dissemination. The style they developed was to replicate their experiments in their publications by including a literal rendition of the original problem, followed by an explanation of the results. In 1974 Kahneman and Tversky published an article called "Judgment under Uncertainty: Heuristics and Biases" in the Journal Science (Tversky and Kahneman 1974). It was a seminal article laying out the basics of the Heuristics and Biases and Program. Reflecting on the possible reasons for its appeal beyond the disciplinary boundaries of psychology, Kahneman writes:

The Science article turned out to be a rarity: an empirical psychological article that (some) philosophers and (a few) economists could and did take seriously. What was it that made readers of the article willing to listen? I attribute the unusual attention at least as much to the medium as to the message. Amos and I had continued to practice the psychology of single questions, and the Science article-like others we wrote-incorporated questions that were cited verbatim in the text. These questions, I believe, personally engaged the

Tversky, A. and D. Kahneman (1983), “Extensional Versus Intuitive Reasoning: The Conjunction Fallacy in Probability Judgment." Psychological Review 90(4):293-315. 
readers and convinced them that we were concerned not with the stupidity of Joe Public, but with a much more interesting issue: the susceptibility to erroneous intuitions of intelligent, sophisticated, and perceptive individuals such as themselves (Kahneman 2002).

In their analysis of the creation of matters of facts in Robert Boyle's experimental program in the seventeenth century, Shapin and Schaffer posit the use of three interconnected technologies: a material technology (the uses of the experimental hardware); a literary technology (dissemination of the results); and a social technology (rules about how to deal with competing knowledge claims) (Shapin and Shaffer 1985). These technologies, they write, functioned as an "objectifying resource," working to give matters of fact the appearance of objectivity (Shapin and Shaffer 1985).

Within the literary technology used for the purpose of disseminating results, Shapin and Schaffer posit further that what it did was allow others to become indirect or "virtual witnesses" to the experiments. The notion of witnessing as literary technology was an important tool for consensus building and, importantly, for persuasion. As they put it, "The literary technology of virtual witnessing extended the public laboratory in offering a valid witnessing experience to all readers of the text" (Shapin and Shaffer 1985). Witnessing, then, creates community by allowing for consensus building and the creation of matters of fact; truth lives where it is agreed upon, and where there is a community to sustain that agreement.

In the quote above, Kahneman exemplifies Shapin and Shaffer's notions of virtual witnessing and extending the public laboratory. Through the lens of virtual witnessing, the quote reads as an acknowledgement of the power of his and Tversky's habit of citing verbatim the questions in the dissemination process to allow the reader to become a virtual witness to the original experiment, and, by extension, to be enrolled in the truth claims supported by the experimental results.

But there is also a sense in which the combination of Kahneman and Tversky's choice of method (questionnaires with quiz-like choice problems) together with their dissemination practices (the straightforward replication of their experiments) collapses the distinction between actual and virtual witnesses. Kahneman writes that he believed that including the questions from the original experiments verbatim engaged readers and convinced them that they were not "concerned with the stupidity of Joe Public" but with the intuitions of "individuals such as themselves" (Kahneman 2002). In other words, Kahneman and Tversky's process of dissemination means that readers not only see the experiment unfold, but also, because the experiment is what is rendered on the page, become subjects in the experiments. The call to readers to participate as subjects is underscored by the form the dissemination takes. The analytical segments of the articles are broken up by descriptions of the experiment in its original form. Presentations of the results and the analysis are thus interrupted by moments that transport the reader into the experimental space. The questions are set apart from the rest of the text so that the reader gets a chance to participate in the experiment before finding out the results. It is "show and tell" in textual form. 
This technique-to transform readers into subjects-is a compelling method of persuasion. Think back to the example of the Linda Problem. Did you follow along with the questions? Did you in effect take part in the experiment as you were reading? And what was your experience reading it? Did it make you more or less convinced of the validity of Kahneman and Tversky's research program?

Part of the success of the technique of enrolling virtual witnesses in Boyle's 17 century experiments was that it had the power to convince experts of the truth of the knowledge claims produced through them. It is no coincidence that Kahneman's reflections on this aspect of their dissemination practices relates to convincing "intelligent, sophisticated, and perceptive individuals" that the results of their experiments applied to them, as well. It was crucial for Kahneman and Tversky not to leave any doubt as to the results applying to experts as well as to non-experts to underscore the universality of their psychological program.

In Thinking, Fast and Slow (2011), Kahneman's autobiographical popularization of the Heuristics and Biases Program, he writes about their method that it was "crucial: if we had reported results of only conventional experiments, the article would have been less noteworthy and less memorable. Furthermore, skeptical readers would have distanced themselves from the results by attributing judgment errors to the familiar fecklessness of undergraduates, the typical subjects in psychological studies" (Kahneman 2011, 13).

In other words, making readers into experimental subjects not only strengthens the experimental results in the dissemination process but is also an effective way to ensure that there is a lack of opportunity to resist the message and the rationale that underpin the program of research. As subjects, readers become vehicles for the truths presented to us and for the robustness of the Heuristics and Biases Program. Enrolling readers as subjects prevents us from distancing ourselves from the subjects in the original experiment. The drive to overcome the skepticism that Kahneman and Tversky were expecting is built into the program and is turned into the strength of its message through the dissemination process. What is more, because you (the reader) become witness to yourself taking part in the experiment, this dissemination practice makes you both experimenter and subject. This serves to further enroll you into the rationale of the project, and once again leaves you with few options for resistance (or distance).

Furthermore, as I discovered in Singapore, this creation of experimenters does more than build robustness for the program. It invites further dissemination and enrollment. When I emulate Kahneman and Tversky's dissemination process in talks or in papers, I administer the test myself, and become, not a virtual, but an actual witness to its effects. Additionally, the process creates a community of people who by virtue of collectively making the mistakes that the experiment is set up to make them do were both enrolled into the rationale of the program and simultaneously given the tools to spread the message further.

Rappert and Coopmans (2015) have shown how making knowledge claims and claims to expertise in a variety of contexts often involves a complex balance between revealing and concealing. In the case of Heuristics and Biases, revealing the experimental procedure in the dissemination process acted as an objectifying resource. It helped make the truth of Kahneman and Tversky's results undeniable, not by excluding the subjective, but by carving out a window 
through which you can see yourself, gathering, giving, processing, and understanding the information. The net result is the impression that we have taken part in the production of the claims presented.

In addition to revealing the experimental procedure, in Kahneman and Tversky's papers, readers are commonly told (or at least given hints) about the kind of illusion/error/heuristic to be tested before the door to the experimental space is opened. This further increases the persuasive power of the revelation since it reinforces the idea that even with what amounts to powerful hints about "the correct answer" the majority of people fail to give it. Readers then become not only subjects in the experiments they read about, but prepared and informed participants who nevertheless most often cannot help but confirm the results. In some ways, then, the experiment that takes place in the dissemination process is even more powerfully persuasive than the results of the original experiment that it emulates. Throughout the process, the reality of deviations from rational and logical thinking are established as readers make the same mistakes as the original subjects even when they try not to, and, importantly, regardless of whether or not they initially believe that making the distinction between rational and logical thinking and actual thinking is reasonable, useful, or even legitimate.

However, the task of showing that actual human decisions deviate from normative decision theory by enrolling readers as subjects is only half the process. The crucial other half relies on the ability of the subject to see and understand the appeal of the normative theory as normative. This is the step on the dissemination process that most closely resonates with historians who argue that much of the appeal of heuristics and biases and behavioral economics stems from the use of neo-classical norms as yardstick from which to measure decision-making (Sent 2004; Heukelom 2014).

Eldar Shafir, in an introduction to a collection of Tversky's writing, makes the following observation:

The beauty of the work was most apparent in the interplay of psychological intuition with normative theory, accompanied by memorable demonstrations. The research showed that people's judgments often violate basic normative principles. At the same time, it showed that they exhibit sensitivity to these principles' normative appeal (Shafir 2004).

In other words, Kahneman and Tversky's experiments showed that we, the reader/subjects, display a readiness to accept the normative validity, the correctness, of logical and statistical principles and to admit that when we deviate from them, we are in the wrong. On the face of it, this is un-intuitive. Admitting to being wrong is often painful and difficult. There is nothing in Kahneman and Tversky's approach to human psychology to suggest otherwise. So, what was it about the process, form, and content of their experiments that allowed people to intuitively understand the normativity of the logical and statistical rules embedded in them, despite these potentially uncomfortable consequences?

At least part of the answer lies in how self-evidently the normativity of the principles is treated in the theoretical foundations of heuristics and biases, and consequently in the 
experimental practices designed to test them. As a taken for granted part of the framework for the program, the normative validity of logical principles, such as the conjunction rule in the Linda Problem, is never questioned. Treated with such self-evidence, far from being an obstacle to acceptance, the program draws persuasive power from the familiar negative feelings produced by being wrong. Our embarrassment at being wrong fuels our desire to be right and leads us to accept the normativity presented to us without question.

Once again, my experience in Singapore can help shed light on my original question about the tension I felt toward behavioral economics in general and my desire to learn more about what behavioral economists had to say. I gave the talk the title: "Are Humans Rational or Irrational?" I could not resist the temptation to mobilize the notion of rationality in the title of the talk on the assumption that it would help draw an audience. In doing so, I realize that I became complicit in the very same provocation and desire to "be better" that I sensed when I enrolled in the Ariely's online course (and that alerted me to the field in the first place). I would like to claim that this move was largely unconscious on my part, but it was not. Once again, the key to understanding why I made this choice lies in the history that I was writing at the time, but this time, in the history of the behavioral economists who built their discipline on the foundations laid in the Heuristics and Biases Program.

\section{Behavioral Economists Mobilizing Rationality}

A key part of the process of writing the history of behavioral economics was the analysis of the archival data I collected from the Russell Sage Foundation records at the Rockefeller Archive Center in April and May 2014. The collection contains the papers of Eric Wanner, vice president at the Alfred P. Sloan Foundation (1982-1986) and president at the Russell Sage Foundation (1986-2013). Wanner was also the founder and long-time champion of the Behavioral Economics Program (1984-1992), a program dedicated to supporting research that combined psychology and economics and that played a central role in the formation of behavioral economics as a field.

In the early days of the formation of the discipline, during the 1980's and the beginning of the 1990's, behavioral economists worked hard to establish their field as a branch of the economic sciences. This meant, among other things, that initially their primary audience was mainstream economists. Comments that express their perceived difficulties of being taken seriously by mainstream economists are strewn across the archival material of the Russell Sage Foundation records. Henry Farber expressed it succinctly, writing: "economists' heads turn only very slowly and with great difficulty." ${ }^{9}$

When the program was set up, Wanner and his Advisory Committee were keen to create a substantive research program that took the descriptive failure of the rationality principle-the idea that humans act and think as rational agents-for granted. Importantly, they worked toward a program engaged in the creation of knowledge about how economic actors actually function, as

, Correspondence from Henry Farber to Eric Wanner, June 3, 1992, SG2-S7, Box 196, Folder 1442, Russell Sage Foundation records, Rockefeller Archive Centre. 
opposed to one that mainly focused on disproving the descriptive validity of the rationality principle. In other words, the ambition was to create a field that investigated economic behavior, as opposed to one mainly focused on justifying its own existence by proving that the rationality principle was descriptively inaccurate.

Nevertheless, much of the Behavioral Economics Program functioned as something like a factory for establishing psychological deviations from rational norms. Early converts to behavioral economics understood the project of identifying and proving the existence of these deviations as a frustrating but necessary first step in the establishment of the field, which was justified by appeal to how deeply rooted the rationality principle was perceived in mainstream economics. Richard Thaler, economist and early adopter and discipline builders of behavioral economics, reflects on this beginning period, writing:

the 80 's was a frustrating period in many ways because so much of our efforts were focused on legitimizing our enterprise. In 1980 the rational expectations school of macroeconomics was in its glory, at [sic] this line of thinking reflected a common aesthetic in economics: rationality is good, and more is better. ${ }^{10}$

One of the more salient expressions of these legitimizing efforts was Thaler's own "Anomalies column" published in the Journal of Economic Perspectives. The Journal of Economic Perspectives was established in 1987, and the first installment of Thaler's column appears in its very first edition. Thaler had come up with the idea from an informal conversation with economist Hal Varian, who had been appointed advisory editor for the journal. Varian informed Thaler that the editorial board was considering commissioning a series of regular short features to be published in the journal. Together they ran the idea of a feature on "anomalies" by the editor Joseph Stiglitz, who approved it (Thaler 2015).

The anomalies column was, for Thaler, quite deliberately a way to cement the notion that the rationality principle lacked descriptive validity. The idea was that enough examples of deviations from normative models of decision making applied to economic decisions would force economists to take the psychology of the consumer seriously, and eventually create a "paradigm shift" for economics:

If necessary, defenders of the traditional paradigm could always find some economics version of an epicycle with which to rationalize an otherwise embarrassing fact. And each single anomaly could be dismissed as a one-off puzzle, for which a satisfactory explanation was sure to exist if one looked hard enough. To create a real paradigm shift, I felt that we would require a whole series of anomalies, each calling for its own ad hoc explanation (Thaler 2015, 170).

10 Correspondence from Richard Thaler to Eric Wanner, Participant Evaluation, May 27, 1992, SG2-S7, Box 196, Folder 1442, Russell Sage Foundation records, Rockefeller Archive Centre. 
The column is one of Thaler's most famous contributions to spreading the behavioral economic gospel. It consisted of a series of short articles, each explaining one or more flaws in neo-classical economic theory and spelling out the experimental evidence that supported the deviation.

Thaler's allusion to Kuhn in naming the column was also deliberate. The first of the twelve features entitled "The January Effect" began with a quote from Kuhn's 1962 The Structure of Scientific Revolutions: "Discovery commences with the awareness of anomaly, i.e., with the recognition that nature has somehow violated the paradigm-induced expectations that govern normal science" (Kuhn 1962, 52). The feature continued with a presentation of a cognitive puzzle, followed by a statement about the aims of the column:

This feature will report successful searches for disconfirming evidence-economic anomalies. As suggested by Thomas Kuhn, an economic anomaly is a result inconsistent with the present economics paradigm. Economics is distinguished from other social sciences by the belief that most (all?) behavior can be explained by assuming that agents have stable, well-defined preferences and make rational choices consistent with those preferences in markets that (eventually) clear. An empirical result is anomalous if it is difficult to "rationalize," or if implausible assumptions are necessary to explain it within the paradigm (Thaler 1987, 198).

With his brief clarified-to report on evidence that disconfirmed the rationality principle-Thaler admits that whether or not the evidence can be rationalized and whether alternative "rational" explanations are implausible is a question of judgment. For this reason, he invites readers to submit their explanations of any of the anomalies that he reports in the column, which he will consider for publication with the stipulation that the suggested explanations are at least in principle falsifiable (Thaler 1987).

It is notable that Thaler chose this way of signaling trust in his own convictions, effectively "daring" the reader to find ways of defending the rationality principle. It was also an effective way of creating a community of economists and an identity for prospective behavioral economists as economists brave enough to challenge their training in neo-classical economics and re-consider the descriptive validity of the rational actor.

Thaler's approach to disseminating findings from the then very young field of behavioral economics is a strong indication that he, just like Kahneman and Tversky before him, anticipated resistance from his primary audience (in Thaler's case, neo-classical economists) and built that anticipation into the dissemination process. With his "anomalies tactic," Thaler expertly constructs an identity for the behavioral economist as a rebel and an underdog.

This David and Goliath narrative does not quite chime with the substantial support that he himself received from the Russell Sage Foundation through a program dedicated to growing the field, or indeed from the Journal of Economic Perspectives, the very platform that Thaler used to establish the narrative. But the tactic and the narrative were effective. Kahneman is one among a fair few of the participants of the program who attributes no small part of the improvement in the 
standing of behavioral economists to the column, which he doubts would have existed without the support of the Russell Sage Foundation."

In 1992 the Russell Sage board of trustees made a decision to review the future of the Behavioral Economics Program at the foundation. This prompted Wanner to send a letter asking all the Behavioral Economics Program grant recipients to review the role of the program in the progress of behavioral economics as field over the past 8 years. ${ }^{12}$ The result of this effort to prolong the foundation's engagement with behavioral economics is a collection of letters that contain reviews of the achievements of the program so far, and of the direction that recipients believed that behavioral economics should take in the future.

It is clear from these letters that behavioral economists had become increasingly focused on public policy as a way to establish the field further and that there was a growing sense among behavioral economists that the policy route would be the most effective way to change the field of economics from within without displacing the strong position of the economic sciences in public policy.

Evidence from the Russell Sage Foundation records shows how behavioral economists linked a focus on policy with improving the empirical foundations of economic theory, since policy is an area where theory is applied. Kahneman was one of the most avid proponents of the idea that behavioral economists ought to begin focusing more heavily on policy. For him, the importance of the cross-disciplinary conversation that is behavioral economics lay precisely in the extent to which economic theory informs policy, writing, "In practice economics is the only science of domestic policy." ${ }^{13}$

In what can be read as a heuristics and biases-like diagnosis of the art of policy making, Kahneman argued that in light of the complexity and uncertainty involved, policy makers are rightly guided by the general assumptions upon which they make educated guesses. Policy makers, so the argument went, were currently using the only heuristic they know, which to a significant degree was based on assumptions imported from neo-classical economic theory. Because this was the case, the assumptions of neo-classical economic theory should become a concern for everyone who wished to inform social policy. To summarize his line of argument, he borrowed the modified slogan coined by Amitai Etzioni and his group of socio-economists that "economic policy is too important to be left to economists." ${ }^{14}$

In other words, Kahneman argued that policy could provide an arena for behavioral economists to challenge the neo-classical monopoly in the economic discipline without challenging the place of economics in policy. As Kahneman put it:

"Correspondence from Daniel Kahneman to Eric Wanner, May 25, 1992, SG2-S7, Box 196, Folder 1442, Russell Sage Foundation records, Rockefeller Archive Centre.

${ }_{12}$ Correspondence from Eric Wanner to grantees of the Behavioral Economics Programme April 30, 1992, SG2-S7, Box 196, Folder 1442, Russell Sage Foundation records, Rockefeller Archive Centre.

${ }_{13}$ Correspondence from Daniel Kahneman to Eric Wanner, May 25, 1992, SG2-S7, Box 196, Folder 1442, Russell Sage Foundation records, Rockefeller Archive Centre.

${ }^{14}$ Ibid. 


\begin{abstract}
Although I share many of Etzioni's doubts about the wisdom or [sic] relying on economics as the sole basic science of policy, I think that the attempt to wrestle economics for control is futile. On the assumption that economics will remain the science of policy for the foreseeable future, the only way to "humanize" or "socialize" the intellectual foundations of policy is by an internal change in the presuppositions of the discipline. In my view, this is one of the principle missions of the behavioral economics program at RSF."t
\end{abstract}

This drive to change economics from within the discipline of economics and not in opposition to it was an attitude that Kahneman credited Eric Wanner for having had since the program's inception. ${ }^{16}$ But the success of the balancing act that is improving a discipline without being perceived as a challenge to it is very much connected to issues of disciplinary hierarchy. Disciplinary hierarchy also has implications for reaching the intended audience of an intellectual product. Other economists were ultimately the intended audience of the early behavioral economists, and finding ways to capture the interest of mainstream economics needed to be part of behavioral economists' agenda. In Kahneman's analysis, because the status of economics is higher than "the disciplines from which it could learn something," publication in journals of specific disciplinary allegiance is necessary. According to Kahneman, Thaler's anomalies column was an exemplar of this strategy:

Like the status of economists in policy making [...] mildly arrogant attitudes are not a useful topic of complaint; they are simply a fact of life. My impression is that Eric was very wise in adopting the view that economists are the ultimate consumers of the intellectual product of the behavioral economics program, and that it is necessary to accommodate their current tastes in the hope of eventually improving their tolerance of new intellectual flavors.

Both the anomalies column and the drive from within the field of behavioral economics to become influential in the public policy arena exemplify the persuasive techniques that behavioral economists had begun to develop, partially inherited from the Heuristics and Biases Program, driven by the necessity to convince the skeptical in service of the survival of their research program. By addressing themselves to their toughest audience (neo-classical economists) early on, behavioral economists honed their skills of persuasion.

The discursive use of the rationality/irrationality dichotomy was a result of the audience that they were addressing. Neo-classical economists were attached to both the normative and the descriptive validity of the rationality principle. Persuading them of the virtues of behavioral economics required training in rational economic theory, and a steady bombardment of evidence

is Ibid.

${ }^{16}$ Ibid.

"Correspondence from Daniel Kahneman to Eric Wanner, May 25, 1992, SG2-S7, Box 196, Folder 1442, Russell Sage Foundation records, Rockefeller Archive Centre. 
of instances when human behavior deviated from that theory, particularly in areas where the rationality principle was strong.

By mobilizing the methods and dissemination practices of the heuristics and biases program, behavioral economists were also able to enroll an interested lay public. Lay publics represented a group of people that were not necessarily attached to the discipline of economics but could be drawn in using the provocation of irrationality and by their (presumed) desire to be rational. This was the tension that I experienced when I first came across the knowledge claims of behavioral economists and the reason why I opted to use the same tactic to draw my audience in Singapore.

\section{Conclusion: What I Learnt About How I Learnt About Behavioral Economists}

Behavioral economists have a history of marketing themselves excellently, effectively, and in ingenious (if not entirely new) ways. The psychologists and economists that laid the foundations of behavioral economics have done a fantastic job of making the world pay attention to the knowledge they produce.

As other historians have noted before me, the history of the formation of behavioral economics is not quite the story that behavioral economists tell about themselves. Sent (2004) in particular has provided an account that complicates the narrative of the field as a critique of neoclassical economics and the rationality principle. She shows how a combination of problems with their mathematical models encountered by mainstream economists and the retention of neoclassical economics as the normative core added to the appeal and acceptance of psychological insights into mainstream economics.

Zooming in on the techniques of experimentation and dissemination established by Kahneman and Tversky complements accounts that place the nexus of the success of behavioral economics within larger institutional and disciplinary change. Taking an autobiographical approach to the topic contributes to these accounts by emphasizing the story of the making of behavioral economics as a story of persuasion. The target audience of behavioral economists has changed over time. They began by addressing neo-classical economists, but increasingly their attention shifted to focus on various publics and policy makers.

Throughout, behavioral economists made use of a particular way of disseminating psychological knowledge that was established by Kahneman and Tversky in the making of the Heuristics and Biases Program. Focusing on the moves made by Kahneman and Tversky and behavioral economists after them, to enroll mainstream economists, to make inroads into policy, and to capture the public imagination highlights the centrality of how behavioral economists disseminated their knowledge, and crucially, to whom.

The more I dug into the history of the making of behavioral economics and the people who built it, the more I felt I could relate to the field and the kind of knowledge behavioral economists were producing. At the same time, I came to the subject from a place of skepticism about the advisability of measuring human rationality. This mix of admiration and provocation 
created a palpable tension that eventually led me to the questions I set out to answer in this paper.

Asking reflexive questions about how I came to study the history of the Heuristics and Biases Program and behavioral economics has highlighted the mechanisms that allowed for people who are skeptical, forewarned, and even outright rivals nevertheless to concede some territory to behavioral economists on the intellectual landscape. It draws attention to the idea that strength of the field lies precisely in the tension I felt when I first engaged with it, a tension that took expression in the oscillation between rationality as a norm, and irrationality as an undeniable human characteristic; not all bad, but not all good either.

I was never entirely enrolled into the practice of psychologizing, or perhaps more accurately, pathologizing, economic behavior. Like many of the authors cited in the introduction, I had reservations about behavioral economists' knowledge claims, and I still do. All the same, I quickly understood the basic premise and grasped the sense that it made. And it clearly makes sense to some of my colleagues, too. Every other shelf in our department is adorned with a copy of Thinking, Fast and Slow. I've had comments on the various copies of popularizations of behavioral economics on my shelves, and my answer as to why I have them is always the same: "It's my thesis topic. What's your excuse?"

While digging into the history of behavioral economics I also discovered to my surprise that the narratives that behavioral economists told about themselves had a lot in common with my own constructed narrative about the origins of STS, particularly in relation to the Strong Programme. One of the many elements that fascinated me about the sociology of knowledge and drew me to it was the air of rebelliousness built into the narrative I received about Bloor and Barnes at the Science Studies Unit at the University of Edinburgh. The narratives around the Science Studies Unit and behavioral economics both hinge on an identity as a challenge to orthodoxy.

In the course of writing this paper I have had to confront another question that has come out of studying Heuristics and Biases and behavioral economics: to what extent is it possible to leverage the dissemination methods cultivated in these fields to disseminate the kind of work that I produce in the vein of what I consider the core principles of STS (assuming there are core principles of STS)? Is there some way of using the robustness created by the dissemination methods of Heuristics and Biases and behavioral economics for disseminating a view of the world and of knowledge grounded in radical relativism and a desire to de-essentialize?

Whether I like it or not, behavioral economists are convincing. As I steel myself to intervene with behavioral economics, a field which to a significant degree shares the same object of study as mine--the study of how humans think and act-I realize that part of that project of intervention for me is beginning to understand how they do what they do so effectively. I don't have to prescribe to what behavioral economists are saying, but I am not going to let it keep me from taking on board that dissemination matters. This is what I learnt about how I learnt about behavioral economists. 


\section{Author Biography}

Zara Thokozani (Thoko) Kamwendo is a sociologist and historian of science working at St John's College, Durham University. Her work is grounded in the Sociology of Scientific Knowledge (SSK) and her research interests include notions of rationality, the psychology of risk and bias, the relationship between the construction of scientific and religious knowledge, and the correlation between funding cultures and discipline formation.

\section{Acknowledgements}

I am very grateful to Daniel Kahneman and Eric Wanner who graciously agreed to talk to me about their work, and to the staff at the Rockefeller Archive Center for guiding me through the process of accessing the material in their custody. Thanks also to my PhD supervisors, Professors Jane Calvert and Steve Sturdy at the University of Edinburgh for supporting me so competently through producing the thesis. Much gratitude is due to my colleagues Catelijne Coopmans, Deborah Scott, and Morgan Currie for patiently helping me draft the manuscript. And, finally, many thanks to Katie Vann and the editing team of ESTS, and to the anonymous reviewer for their helpful and insightful comments.

\section{References}

Ariely, D. 2008. Predictably Irrational: The Hidden Forces That Shape Our Decisions. London: Harper Collins.

Barton, A. and T. Grüne-Yanoff. 2015. "From Libertarian Paternalism to Nudging—and Beyond." Review of Philosophy and Psychology 6(3):341-359.

Bloor, D. 1991. Knowledge and social imagery (2nd ed.). Chicago \& London: University of Chicago Press.

Bovens, L. 2009. "The Ethics of Nudge" in Preference Change: Approaches from Philosophy, economics and psychology edited by T. Grune-Yanoff and S-O. Hansson. 207-219. New York: Springer.

Brafman, O. and R. Brafman. 2008. Sway: The Irresistible Pull of Irrational Behaviour. New York: Doubleday.

Gilovich, T. 1993. How We Know What Isn't So: The Fallibility of Human Reason in Everyday Life. New York: Free Press.

Gladwell, M. 2005. Blink: The Power of Thinking Without Thinking. London: Allen Lane.

Goodwin, T. 2012. “Why We Should Reject Nudge." Politics 32(2):85-92.

Graf, R. 2019. "Nudging before the nudge? Behavioural safety regulation and the rise of behavioural economics" in Handbook of Behavioural Change and Public Policy edited by H. Straßheim and S. Beck. 23-37. Cheltenham, UK; Northampton, MA, USA: Edward Elgar.

Heukelom, F. 2012. "Three Explanations For The Kahneman-Tversky Programme of The 1970s." The European Journal of the History of Economic Thought 19(5):797-828.

Heukelom, F. 2014. Behavioral economics: a history. New York: Cambridge University Press. 
Jones, R. J. Pykett and M. Whithead, eds. 2013. Changing Behaviours: On the Rise of the Psychological State. Cheltenham, U.K: Edward Elgar.

Kahneman D. 2011. Thinking, Fast and Slow. London: Penguin.

Kahneman, D. 2002. “Daniel Kahneman - Biographical." 2014. Accessed June 12, 2019. http:// www.nobelprize.org/nobel_prizes/economicsciences / laureates/2002/kahneman-bio.html.

Kahneman, D. and A. Tversky. 1972. "Subjective Probability - Judgment of Representativeness." Cognitive Psychology 3(3):430-454.

Kuhn, T. S. 1962. The Structure of Scientific Revolutions. Chicago: University of Chicago Press.

Kusch, M. 2007. "Towards A Political Philosophy of Risk: Experts And Publics In Deliberative Democracy." In Risk: Philosophical Perspectives, edited by T. Lewens. 131-155. Oxon and New York: Routledge.

Oliver, A. 2017. The Origins of Behavioural Public Policy. Cambridge: Cambridge University Press.

Pooley, J., and M. Solovey. 2010. "Marginal to the Revolution: The Curious Relationship between Economics and the Behavioral Sciences Movement in Mid-Twentieth-Century America." History of Political Economy, 42(1): 199-233.

Rappert, B. and C. Coopmans. 2015. “On Conveying And Not Conveying Expertise." Social Studies of Science 45(4):611-619.

Sent, E.-M. 2004. "Behavioral economics: How psychology made its (limited) way back into economics." History of Political Economy 36(4):735-760.

Shafir, E. ed. 2004. Preference, Belief, and Similarity: Selected Writings. Cambridge Massachusetts, Bradford Books, MIT Press.

Shapin, S. and S. Shaffer. 1985. Leviathan And The Air-Pump: Hobbes, Boyle, And The Experimental Life: Including A Translation Of Thomas Hobbes, Dialogus Physicus De Natura Aeris By Simon Schaffer. Princeton, N.J.: Princeton University Press.

Shiller, R. J. 2000. Irrational Exuberance. Princeton, N.J.: Princeton University Press.

Straßheim, H. and Beck, S. eds. 2019. Handbook of Behavioural Change and Public Policy. Cheltenham, UK; Northampton, MA, USA: Edward Elgar.

Straßheim, H. 2020. "The Rise and Spread of Behavioral Public Policy: An Opportunity for Critical Research and Self-Reflection." International Review of Public Policy, 2(1), 115-128.

Thaler, R. 1987. “Anomalies: The January Effect." Journal of Economic Perspectives 1(1):197-201.

Thaler, R. 2015. Misbehaving: The Making of Behavioral Economics. New York, W. W. Norton and Company.

Thaler, R. and C. Sunstein. 2008. Nudge: Improving Decisions About Health, Wealth and Happiness. New Haven and London: Yale University Press.

Tversky, A. and D. Kahneman. 1974. "Judgment Under Uncertainty - Heuristics And Biases." Science 185(4157):1124-1131.

Tversky, A. and D. Kahneman. 1983. "Extensional Versus Intuitive Reasoning: The Conjunction Fallacy in Probability Judgment." Psychological Review 90(4):293-315.

White, M. D. 2017. “Nudging Debt: On the Ethics of Behavioral Paternalism in Personal Finance.” Journal of Financial Counseling and Planning 28(2):225-234 
White, M. D. 2019. "Nudging Merit Goods: Conceptual, Normative, and Practical Connections." Forum for Social Economics: Meritorics and Paternalism 48(3):248-63.

Whitehead, M., Jones, R., Lilley, R., Pykett, J., \& Howell, R. (2018). Neuroliberalism: Behavioural Government in the 21st Century. London and New York: Routledge.

\section{Unpublished Material}

All archival material was collected from the Russell Sage Foundation records collection, Subgroup 2, Series 7, Rockefeller Archive Center, Sleepy Hollow, New York, USA. 